tion is only about 3 per cent. greater than that of the exciting one, and is about inversely proportional to the sixth power of the atomic number, we get $v=2.23 \times 10^{8}(M-I) \mathrm{cm}$. $/ \mathrm{sec}$, while Bohr finds $(\mathrm{M}=\mathrm{N})$ :

$$
v=2 \cdot 18 \times 10^{8} \mathrm{~N} \mathrm{~cm} . / \mathrm{sec} \text {. }
$$

Now from this value of $v$, and $v=2.47 \times 10^{15}(\mathrm{M}-\mathrm{I})^{2}$, we can calculate $x$ from $x m v^{2}=2 h v$, which must be a constant, because both $v^{2}$ and $v$ depend on $(M-I)^{2}$. As $m v^{2} / 2$ is energy to be, at least in part, radiated away periodically, on the right side of the equation, not only the number of times energy is radiated away per second $(v)$, but also the total time of radiation $(t)$ and the mean energy radiated away per period (E) must occur, so that $x m v^{2}=2 t v \mathrm{E}$, and $t \mathrm{E}$ is a constant (which may mean only that the time during which radiation is emitted is inversely proportional, for a given frequency, to the quantity of energy that is radiated away during each period). Hence

$$
x=2 h v / m v^{2}=2.6 .62 \times 10^{-27} \cdot 2.47 \times 10^{15}(\mathrm{M}-\mathrm{I})^{2} /
$$$$
0.88 \times 10^{-27} \cdot 2 \cdot 23^{2} \times 10^{16}(\mathrm{M}-\mathrm{I})^{2}=0.748 \text {, or } 3 / 4 \text {, }
$$

as assumed by Moseley.

From $m v^{2} / a=e^{2}(\mathrm{M}-1) / a^{2}$ we can calculate $\operatorname{mav}=e^{2} \cdot(\mathrm{M}-\mathrm{I}) / v=4 \cdot 78^{2} \times 10^{-20}(\mathrm{M}-\mathrm{I}) / 2 \cdot 23 \times 10^{8}(\mathrm{M}-\mathrm{I})$ $=\mathrm{I} \cdot 03 \times 10^{-27}$, while $h / 2 \pi=6.62 \times 10^{-27} / 2 \pi=1.05 \times 10^{-27}$, so that $m a v=h / 2 \pi$, as assumed by Bohr, and

$$
a=5.12 \times 10^{-9}(\mathrm{M}-\mathrm{I})^{-1} \mathrm{~cm} \text {. }
$$

All this is in agreement with Bohr's theory.

As may be seen from a previous letter (NATURE, March 5, 19I4, p. 7), some properties of the elements depend not on the atomic but on the "periodic" number $\mathrm{P}=8 r \pm b$ ( $r$ is the number of horizontal rows preceding that of the element period of rare-earth elements not counted, and $p$ the maximum or positive valency). Now the sum of these electrons of valency may be easily seen to be for all regular (nonelementar) inorganic molecules an integer multiplum of eight. Hence the same holds for the sum of all $\mathrm{P}$ electrons in these molecules (ions and rare-gasesatoms included). Affinity is then the tendency to build up systems of $8 n$ P-electrons, and, of course, if such a molecule breaks up into atoms with each similar systems of $8 n$ P-electrons, such ions must be formed as known from electrolysis. The great facility with which molecules like $\mathrm{H}_{2} \mathrm{O}, \mathrm{NH}_{3}, \mathrm{HCl}$, though neutral, are added to such systems, may be due to each of them, containing 8 P-electrons. According to Bohr, rings of electrons, whether belonging to one or to more atoms, may unite if the number of electrons in both is equal, so that rings of 2,4 , and ultimately 8 will be the most probable ( 16 only if the charge is very great).

Of course, the objections to the "Saturnian" atom hold for such systems also. Indeed, the structure of the periodic system as a whole, and the curious relation between the number of the non-periodic (Q) elements, $\mathrm{H}, \mathrm{He}, \mathrm{Co}, \mathrm{Ni}, \mathrm{Rh}, \mathrm{Pd}$, and that of the horizontal rows in the periodic system : $2 / 1,2 / 2,2 / 3,4 / 3,4 / 4,4 / 5,6 / 5,6 / 6,6 / 7$, suggests systems of $n$ equal non-coplanar rings of 8 electrons surrounding one or more (even $n$ ), positive nuclei, with $n$ or $n \pm \mathrm{x}$ electrons in or near the axis, and additional rings of electrons of valency, rather than a Saturnian atom. But, generally speaking, Bohr's theory is not in disagreement with the atomic number hypothesis.

Gorsel (Holland), April I5.

\section{Means of Collecting Eelworms.}

THE rhubarb, when cultivated as a field crop, is subject to a wasting disease, which, attacking the rootstock and causing it to decay, occasions considerable loss to the grower. The diseased tissue, when examined, is frequently found to be infested with the stem eelworm, Tylenchus devastatrix, Kuhn, and, in districts where this disease is prevalent, a supply of Tylenchus material is at hand which, since the rhubarb is a perennial plant, is available not only in summer but during winter also.

When pieces of decaying rhubarb tissue are enclosed in a corked tube, any Tylenchus worms that are present migrate to the surface and, provided they have not been corked up too long, will, if placed in water, remain alive for weeks. Material can be obtained in quantity, and with very little delay, by placing pieces of rhubarb in a strainer covered with fine gauze, and suspended in a vessel of water. The eel. worms, forsaking their feeding-ground, wriggle through the muslin and accumulate in a writhing mass on the floor of the vessel. This water method, it may be added, is also useful in examining the eelworm fauna of soil samples, and pro. vides a simple means of ascertaining $\mathrm{roughly}$ what forms are present.

When thus collected from rhubarb, the eelworms are usually mixed with sediment, but this defect can be remedied by placing the material, while still unsorted, in a porous vessel, such as a candlefilter, which, when placed in water, allows only living eelworms to pass through. A better method of cleansing the material, however, is obtained by taking advantage of the habit that eelworms have of climbing up capillary films when these are present. For this purpose, silk threads are employed, to each of which is suspended a blob of cotton-wool, the cotton-wool serving as a receptacle for holding the crude material obtained from the rhubarb. The upper ends of the threads are attached to a glass ring which is supported upon the sloping sides of a funnel-shaped vessel containing water-this shape being chosen in order that the blobs may hang clear.

As the threads become saturated, the eelworms, leaving all impurities behind in the cotton-wool, ascend amongst the silken strands, and, passing over the brim into the water, congregate on the floor of the vessel-a feat on their part which, besides providing the student with clean material, raises the question whether, in respect of their acrobatic accomplishments, eelworms vary to any appreciable extent; and, if so, whether the rough method here described can be extended so as to provide a means of sorting out one species from another, when two or more species are present in the material employed.

M. V. Lebour.

The University, Leeds.

\title{
THE PROHIBITION OF EXPERIMENTS ON DOGS.
}

THE Dogs' Protection Bill for the second reading of which 122 members of Parliament were induced to vote the other day is one of those measures which are born of ignorance and fostered on misrepresentation. All our knowledge of the functions of the body is fundamentally based on experiments which have been made upon dogs. The action of the heart and its nerves; the 
mechanisms of circulation, respiration, digestion, and secretion; the functions of the liver, pancreas, and kidney; the processes of metabolism, the causation of diabetes; the utility of the internallysecreting glands; the manner in which the organs of the body are governed and their functions regulated--none of these could have been elucidated nor could the knowledge which has been obtained have been applied to man from experiments upon animals other than dogs. The prohibition of the employment of dogs for these investigations would put a complete stop to the progress of physiology in Great Britain-which, in this particular science, has, from the time of Harvey onwards, always held a peculiarly honourable position. It would put medicine in this country at an enormous disadvantage as compared with other countries; and our professors and students would have to go abroad to gain that practical knowledge of the functions of the body for the investigation of which the $\operatorname{dog}$ is the only animal available. For medicine is founded upon an exact knowledge of these functions: without it the physician gropes in the dark and works by guesses which are generally far removed from the actual truth. Moreover many diseases which are common to man and animals can only be fully investigated in an animal like the dog, unless man himself is to be made the subject of experiment. And it is scarcely necessary to point out even to our opponents that the prohibition they demand would prevent any further investigation of the causation and treatment of diseases which are peculiar to the dog, so that the race they are professing to protect would ultimately suffer from such prohibition even more than mankind.

The question really at issue is whether a knowledge of the functions of the body in health and disease is to continue to be gained at the expense of a certain number of stray and worthless dogs, which are in any case condemned by law to be destroyed, or at the expense of humanity. Nothing is more certain than that important branches of medical knowledge if not advanced by experiments on these animals can only be advanced by taking toll of the lives of patients, who would be treated in ignorance of the conditions under which remedies should be applied and of the results which such remedies are likely to yield.

It is difficult for a layman to understand the full bearing of this question, because he is unaware of the extent to which medical knowledge profits and has profited by experiments on animals. Some doctors even, mostly belonging to what is often spoken of as the "old school," are uninformed regarding the manner in which their knowledge of the functions of the body and of the changes which are produced in disease has been acquired. It is, moreover, true that the ordinary practising physician does not himself make experiments upon animals: he has as a rule neither the time nor the opportunity. But however welltrained he may be, it is not the practitioner who advances our knowledge of medicine and surgery; or if he does so it is at the expense of the patient upon whom he first makes a trial of the remedies by aid of which he hopes to cure the particular disease he is treating. There are, admittedly, operations which have been tried from the first upon the human subject and have ultimately resulted in singular success, so that cases which previously would have been relinquished as hopeless are in large numbers restored to health. But the toll of human lives required to achieve this success is lamentable. Surgeons who devise a new method of operation are in the habit of publishing statistics regarding the cases which they have treated by it. An examination of such statistics always shows a relatively large per centage of failures and death in the earlier cases, whilst that percentage is greatly reduced or even abolished in the later cases. This means that the earlier cases have partaken of the nature of experiments by the aid of which the technique of the method has been established. If this technique had been worked out in dogs the toll of human life required to arrive at the same degree of perfection would have been vastly less.

There are, however, surgeons of the present day-and their number is likely to increase in the future-who consider it improper to acquire at the expense of their patients the technical knowledge necessary for the establishment of a new operative method and who would willingly resort to dogs for the purpose of obtaining such knowledge. This procedure can, however, be but rarely carried out in this country, because the anti-vivisectionist legislation of recent years places serious obstacles in its path. But in the United States, where a more enlightened view is taken of the position of mankind in relation to the lower animals, it is the recognised method of procedure, and is beginning to make itself felt in the extraordinary progress which the science and practice of surgery has made of late years in America.

Sir Frederick Banbury has attempted to excite sympathy for his Bill by citing the case of a dog which had been operated on by an eminent Edinburgh surgeon, with the object of testing a new method of inducing union of fractures of bone. Surely nothing could be more proper than that a new method should be first performed upon a dog rather than upon man. Does Sir Frederick Banbury think that it would have been right for the test to be first made upon a patient? Would he prefer to have an untried method applied to himself before it had been determined, by experiments upon dogs, whether it could be successfully performed or would be likely to yield a good result? I think the Edinburgh dog is an unfortunate instance for Sir Frederick to have selected. And I cannot, of course, expect him to see that the fact that the dog, which was bought in good faith from a known dealer in animals, happened to have been picked up in the street by the vendor, has nothing to do with the question whether it is or is not expedient to employ dogs for this and similar purposes.

Sir Frederick Banbury is commonly believed to be impervious to argument and one can well

NO. 2323, VOL. 93] 
understind that this may be so; otherwise he would surely be able to see that the very statistics which he gives regarding the number of dogs utilised in this country for medical research furnish the strongest of arguments against his Bill. Does he think that men who are engaged in these researches prefer to employ $\operatorname{dog} s$, and insist on using them, rather than cats or rabbits or guineapigs-for which Sir Frederick evidently has but little sympathy - for no other reason than the sheer desire to vivisect them rather than other animals which are far cheaper and more easily obtained? Is he not able to understand that dogs are never employed and are never likely to be employed for experiments unless there is some special necessity for using these animals rather than others? At any rate he may accept my assurance that it is so. And it follows that the greater number of dogs he can show to have been used the stronger is the argument for the necessity of using them. Not that his statistics are of much account, for in attempting to strengthen his case for dogs, he mixes cats up with them-unless the report of his speech is in this respect inaccurate.

But Sir Frederick Banbury's inability to assess evidence is sufficiently manifested by his argument that because the Royal Commission did not specifically state in its report that it is necessary for dogs to be employed it found no evidence sufficiently strong to authorise it to make such a statement. We know, as a matter of fact, that the Commission did discuss the question whether the exclusion of dogs might be recommended and definitely concluded against the adoption of this course. Is it, perhaps, possible that Sir Frederick Banbury-who puts himself forward as a judge in this matter-has not himself read the evidence which was presented to the Commission on the subject? This is the only hypothesis that I can suggest to render his position intelligible. But this hypothesis cannot be applied to Col. Lockwood, who appears as Sir Frederick's chief supporter-since he was a member of the Commission. Although he does not dare to say that the evidence before the Commission proved that the use of dogs is not necessary, he alleges that it did not distinctly prove "to anyone with a fair mind" that the dog alone is necessary for those "so-called scientific experiments" (sic). And this in spite of the fact that it had been proved to demonstration before the Commission-what is, of course, well known to any person who has any medical knowledge worth speaking of - that most of what we know regarding the functions of the body could only have been elucidated with the aid of experiments on dogs.

Col. Lockwood is, however, good enough to inform us by what consideration he is guided. $\mathrm{He}$ is "not ashamed to say that he is actuated by sentiment." But there is sentiment and sentiment, and we may be permitted to inquire what kind of sentiment it is that actuates Col. Lockwood. Sentiment is feeling and Col. Lockwood's feeling is for the lower animals in general, for dogs in particular, and probably-if it were to be still further analysed-most particularly for the special dog which, as he tells us, he leads about London on a string. His sentiment does not extend to humanity. He has no feeling for his own species. He prefers that mankind shall continue to be ignorant, and shall continue to suffer as a result of that ignorance, rather than that his feeling for dogs, most of which do not in any way suffer, shall be harrowed.

Sentiment of this sort has no true ring: it is false sentiment; and any man-let alone a legislator-should be ashamed to confess that he is actuated by it.

Further, Col. Lockwood is good enough " not to wish to accuse his opponents of not being so humane as himself." But Col. Lockwood's humaneness is-like his sentiment-false : it leaves humanity out of consideration. He may take it from me that his opponents repudiate this kind of humaneness and thank him neither for the comparison nor for his eulogium of their profession. Of what value is eulogium coming from such a quarter? If he and his I $2 \mathrm{I}$ fellow-members accept the services of medical men, are they not benefiting by the very experiments they denounce? To be consistent they should resolutely decline to call in the aid of physician or surgeon and betake themselves to the Christian Scientist or to any other quack they may fancy. But it is as hopeless to look for consistency from anti-vivisectionists as to expect to gather figs from thistles. As for the voters who send such persons to Parliament, one may well apply to them Carlyle's estimate of most of his fellow-citizens. But perhaps they are, on the whole, not inappropriately represented there. $\quad$ E. A. SсHÄFER.

THE TREVOR LAWRENCE ORCHID COLLECTION AT THE ROYAL GARDENS, KEW.

W HEN the late Sir J. J. Trevor Lawrence, Bart., died, an announcement was made that his well-known orchid collection at Burford had been bequeathed to Lady Lawrence with an expression of his wish that such of the plants as were especially of botanical interest should be presented to the Royal Botanic Gardens, Kew. This gift has now been made to the national orchid collection there, which has received from Lady Lawrence a large selection consisting of 580 plants, belonging to 89 genera, and representing 3.50 species mainly, but by no means exclusively, of botanical interest.

The character of the collection brought together by Sir Trevor at Burford during many years was a matter of general knowledge. It was singularly rich in rare and interesting species, owing to the fact that Sir Trevor at all times paid especial attention to whatever in the natural family was striking or unusual from a morphological point of view, apart entirely from any decorative value which it might possess. The result of this was that the Burford collection was not only thoroughly representative of the usual showy species and hybrids and on this account to be

$$
\text { NO. 2323, VOL. 93] }
$$

